\title{
Stage II Pleural Malignant Mesothelioma AJCC v7
}

National Cancer Institute

\section{Source}

National Cancer Institute. Stage // Pleural Malignant Mesothelioma A/CC v7. NCI

Thesaurus. Code C6647.

Stage II includes: T2, N0, M0. T2: Pleural mesothelioma with a tumor involving each of the ipsilateral pleural surfaces (parietal, mediastinal, diaphragmatic, and visceral pleura) with at least one of the following: involvement of diaphragmatic muscle; extension of tumor from visceral pleura into the underlying pulmonary parenchyma. N0: No regional lymph node metastasis. M0: No distant metastasis. (AJCC 7th ed.) 